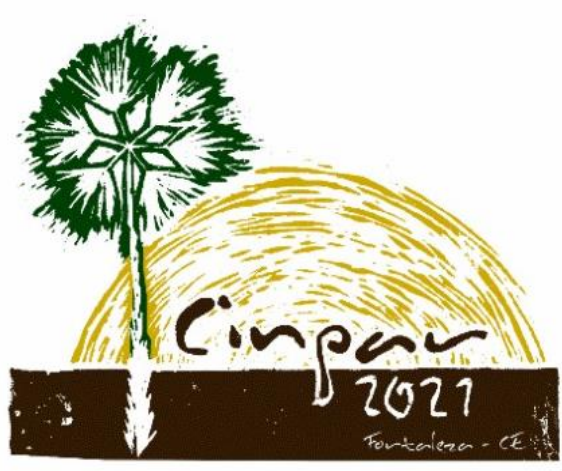

XVII Congresso Internacional sobre Patologia e

Reabilitação das Construções

XVII Congreso Internacional sobre Patología y Rehabilitación de las Construcciones

XVII International Conference on Pathology and Constructions Rehabilitation

FORTALEZA (Brasil), 3 a 5 de junho de 2021

https://doi.org/10.4322/CINPAR.2021.039

\title{
Terra crua como material construtivo sustentável
}

\section{Soil as a sustainable building material}

\author{
Karoline TEIXEIRA ${ }^{1}$, Adriano ANTUNES MONTEIRO ${ }^{2}$, Jessica Maria BEZERRA LEITE ${ }^{3}$, Jorgiane PIRES BEZERRA ${ }^{4}$, \\ Adriane MELO MONTEIRO ${ }^{5}$, Geovane SANTOS BORBA ${ }^{6}$

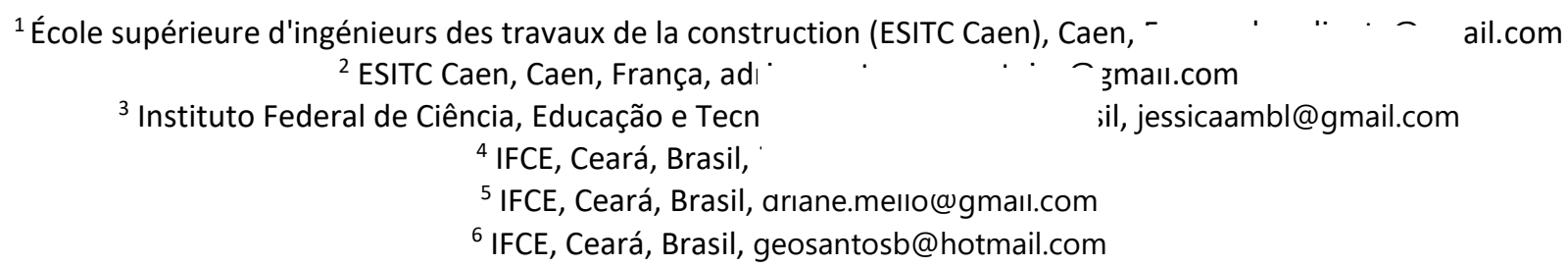

\section{Resumo}

As consequências de impactos ambientais são desafios de todos os setores de atividades econômicas do mundo no século XXI. Contudo, a construção civil é um dos setores que mais consomem recursos e causam impactos ambientais. Sabendo disso, a construção sustentável tem se tornado uma tendência cada vez maior. Ela procura reduzir os impactos ao meio ambiente durante e após a construção, como por exemplo reduzindo o consumo de energia e utilizando materiais de baixo impacto ambiental, como a terra crua. $O$ objetivo desse artigo é apresentar à terra como um material construtivo sustentável, bem como seus métodos construtivos mais utilizados, suas vantagens e desafios. A metodologia utilizada é de revisão de bibliografia entre revistas científicas, dissertações de mestrado e teses de doutorado no assunto. A terra crua é geralmente utilizado para reformas, reparos, reboco de acabamento interno, parede de suporte, reboco interno e quando acompanhado de fibra, este material pode ser utilizado como isolante. Ela apresenta vantagens econômicas, ambientais e de conforto muito importantes e apreciados por arquitetos e construtores.bHá diversos métodos relacionados que utilizam a terra crua como material de base, qual método utilizar vai depender da composição da terra que se tem disponível, no conhecimento tecnico de quem vai utilizalá-la e do tipo de construção que se pretende fazer. Desse modo, conclui-se que esse matérial pode ser considerado um bom matérial sustentável, pois além de outras vantagens, ele é de baixo impacto ambiental se compardo à outros materiais construtivos. Contudo, ainda tem suas limitações e precisa ser mais difundido entre as construções modernas.

Palavras-chave: Engenharia civil. Terra. Material construtivo. Sustentabilidade.

\section{Abstract:}

The consequences of environmental impacts are challenges for all sectors of economic activities in the world in the 21st century. However, civil construction is one of the sectors that consume the most resources and cause environmental impacts. Knowing this, sustainable construction has become an increasing trend. It seeks to reduce impacts on the environment during and after construction, for example by reducing energy consumption and using materials with low environmental impact, such as raw earth. The purpose of this article is to present the land as a sustainable building material, as well as its most used construction methods, its advantages and challenges. The methodology used is to review the bibliography among scientific journals, 
master's dissertations and doctoral theses on the subject. Raw earth is generally used for renovations, repairs, internal finishing plaster, support wall, internal plaster and when accompanied by fiber, this material can be used as an insulator. It has economic, environmental and comfort advantages that are very important and appreciated by architects and builders. who will use it and the type of construction intended to be done. Thus, it is concluded that this material can be considered a good sustainable material, because in addition to other advantages, it has a low environmental impact when compared to other construction materials. However, it still has its limitations and needs to be more widespread among modern buildings.

Keywords: Civil Engineering. Soil. Construction material. Sustainability.

\section{Introdução}

As consequências de impactos ambientais são desafios de todos os setores de atividades econômicas do mundo no século XXI. Contudo, a construção civil é um dos setores que mais consomem recursos e causam impactos ambientais.

Sabe-se que a indústria da construção consome grandes quantidades de materiais. Segundo John (2002, apud CORDEIRO et al. 2018), há estimativas de que nos Estados Unicos, a consumação de materiais para a construção cheguem a $75 \%$ do total, no Japão é cerca de $50 \%$ de toda matéria bruta, na União Europeia as construções consomem $40 \%$ do total de energia e são responsáveis por $40 \%$ dos resíduos gerados e $30 \%$ da emissão de $\mathrm{CO}_{2}$.

Agopyan (2013, apud CORDEIRO et al. 2018),) colabora dizendo que o setor da construção civil é o mais poluente do planeta, sendo responsável pelo consumo de $40 \%$ a $75 \%$ de toda matéria-prima produzida; que a utilização de cimento é maior que o consumo de alimentos e o de concreto só perde para consumo de água; e que são produzidos em média 500 quilos de entulho para cada pessoa, o que equivale a 3,5 milhões de toneladas por ano.

Carvalho e Lopes (2012) afirmam que construir e manter o funcionamento de prédios implicam no consumo de $50 \%$ dos recursos naturais, $40 \%$ da energia e $16 \%$ da água, quantidade bastante elevada, sobretudo porque implica em diversos impactos.

Desse modo, para tentar reduzir os impactos negativos relacionados à utilização de materiais de construção, cada vez mais se incentivam estudos de desenvolvimento de materiais e métodos construtivos que sejam menos impactantes.

A terra, como um material construtivo, é utilizado há milhares de anos em todo o mundo, mas desde a industrialização vem perdendo espaço. Atualmente, ainda é vista como um material associado à pobreza e marginalizado (FRANÇA et al., 2019). No entanto, com as recentes preocupações ambientais, ela vem sendo retomada por arquitetos e engenheiros como um matéral de construção sustentável.

Nessa perspectiva, o resgate das técnicas de construção com terra se torna uma alternativa apropriada para construir habitações sustentáveis, contribuindo para a redução de problema ambientais e sendo atuamente abordado por diversos autores na literatura atual (CORDEIRO, et al. 2018).

Desse modo, o objetivo desse artigo é apresentar à terra como um material construtivo sustentável, bem como seus métodos construtivos mais utilizados, suas vantagens e desafios. Assim, espera-se contribuir com a literatura a respeito da temática de materiais de construções sustentáveis.

\section{Metodologia}

A metodologia utilizada foi de revisão de literatura, baseada em artigos, monografias, dissertações, teses, livros e outras fontes bibliográficas relacionadas à terra como material construtivo.

Desta forma, no que se refere aos procedimentos da pesquisa, a mesma é classificada como pesquisa bibliográfica com abordagem qualitativa, pois a:

A pesquisa bibliográfica é um apanhado geral sobre os principais trabalhos já realizados, revestidos de importância, por serem capazes de fornecer dados atuais e relevantes relacionados com o tema. $O$ estudo da literatura pertinente pode ajudar a planificação do

Terra crua como material construtivo sustentável 
trabalho, evitar publicações e certos erros, e representa uma fonte indispensável de informações, podendo até orientar as indagações (MARCONI; LAKATOS, 2003, p. 158).

Para a elaboração deste estudo, mediante seus objetivos, foi realizada uma pesquisa por meio de informações referentes à construção sustentável em terra crua, nos anos de 2015 à 2020, por meio de um levantamento bibliográfico em publicações nas principais plataformas de pesquisa científica.

Foi ressaltado importância sobretudo em pontos como conceitos, contextualização histórica, vantagens e desvantagens de sua utilização e principais métodos construtivos que utilizam esse matérial como base; pontos que servem de base para discussões sobre a temática abordada.

A elaboração deste trabalho foi dividido principalmente em três etapas: 1 . a pesquisa bibliográfica nos meios de comunicação; 2. leitura e compilação dos dados da literatura; 3. elaboração do artigo dentro dos parâmetros do template.

\section{Resultados e discussões}

A terra é um elemento sedimentar resultante de mudanças biológicas, físicas e químicas, como ação de organismos, clima e erosão, nas rochas presentes no solo (ITULAMYA, 2019). É um material de construção considerado universal, pois pode ser encontrado em todos os continentes e é tão antigo quanto a própria humanidade. É um material largamente utilizado na construção habitacional devido à sua ampla disponibilidade, acessibilidade, tradição e facilidade de uso (GOMES et al., 2019).

Na construção, este material é geralmente utilizado para reformas, reparos, reboco de acabamento interno, parede de suporte, reboco interno e quando acompanhado de fibra, este material pode ser utilizado como isolante (ITULAMYA, 2019).

\subsection{Contexto histórico}

O homem usa as técnicas da terra como material de construção há mais de 9.000 anos, em todas as culturas antigas, tanto para a construção de casas quanto para a construção de templos religiosos (FRANÇA et al., 2019).

De acordo com a UNESCO, $20 \%$ do número de sítios do Patrimônio Mundial são total ou parcialmente construídos em terra. Isso atesta a rica herança arquitetônica de terras brutas (Anger et al. 2011, OLIVA, 2010). A mesquita Djenné no Mali, a cidadela de Chan Chan no Peru, a vila de Ait-Bem-Haddou no Marrocos ou a antiga cidade de Shibam no lêmen, todas classificadas como patrimônio mundial da UNESCO, são exemplos (GOMES et al., 2019).

Atualmente, existem muitas construções, principalmente em áreas rurais da América Latina, Ásia e África. No entanto, a terra é frequentemente vista como um símbolo de pobreza e não se tornou um material amplamente utilizado na construção na Europa (ITULAMYA, 2019).

Na França e em outros países industrializados, a partir do século XIX, tornou-se cada vez menos comum, em comparação com os mais diversos tipos de materiais, como o concreto e o aço, considerados mais modernos e duráveis (ITULAMYA, 2019).

Contudo, a partir da crise de energia da década de 1980 e das preocupações ambientais atuais, a terra crua está ganhando mais atenção devido às muitas vantagens, arquitetos e construtores estão começando a olhar para ela novamente como um material interessante (ITULAMYA, 2019).

A terra deixa de ser sinônimo de pobreza e desconforto e passa a ser encarado como um material alternativo para novas construções, reformas e reabilitações de forma tradicional ou contemporânea.

\subsection{Vantagens e desafios}

A terra é valorizada pelas suas inúmeras vantagens. No entanto, também encontra alguns pontos negativos que podem ser encarados como desafios.

\subsubsection{Vantagens}

Terra crua como material construtivo sustentável 


\subsubsection{Econômicas}

Em geral, a terra está disponível localmente, não requer transporte ou calcinação, tem fácil extração e baixo custo de processamento (GOMES et al., 2019).

Sua transformação é barata e geralmente não querer mão de obra qualificada, precisa apenas ferramentas simples e amplamente acessíveis para sua extração, modificação e uso (ITULAMYA, 2019).

Outro ponto a destacar é que parte da população mundial trabalha e vive graças às construções de barro (GOMES et al., 2019).

\subsubsection{Ecológicas}

Este material possui baixo impacto ambiental devido ao baixo consumo energético dos agregados e às baixas emissões de $\mathrm{CO}_{2}$. Não é um material tóxico, é reutilizável e reciclável, embora não seja renovável (GOMES et al., 2019).

Em comparação à outros materiais, a terra tem um menor indice de impactos ambientais, pois apenas 1 a $2 \%$ de energia é gasta para uma construção semelhante à uma de concreto armado ou tijolos cozidos, por exemplo (FRANÇA et al., 2019).

Sua extração não promove o desmatamento, como é o caso de certas regiões do mundo onde a madeira é utilizada para fazer terracota (ITULAMYA, 2019).

\subsubsection{Conforto}

Devido às características higroscópicas da argila, a terra tem a capacidade de regular a umidade relativa do ambiente interno (GOMES et al., 2019).

A terra armazena calor quando exposta à luz solar e lentamente perde-o quando a temperatura externa é baixa, melhorando assim o conforto térmico dentro do cômodo (FRANÇA et al., 2019).

A terra desempenha um papel de amortecimento acústico e, além disso, a terra crua purifica o ar ambiente filtrando certos poluentes e absorvendo os odores (ITULAMYA, 2019).

\subsubsection{Desafios}

De acordo com Itulamya (2019):

3.2.2.1 Qualidade e disponibilidade

A qualidade e disponibilidade do solo em certas regiões podem ser diferentes de outras regiões, o que leva a uma não padronização do material.

\subsubsection{Clima}

Em regiões de clima temperado, com muita chuva e geadas, este material apresenta propriedades mecânicas reduzidas que limitam sua resistência.

Em regiões de clima equatorial, com grandes variações de umidade, o material é instável, pois se desgasta a cada estação e sem aglutinante estabilizador libera poeira. O solo se degrada ao contato com a água e a umidade, o que dificulta seu uso.

3.2.2.3 Dificuldades de utilização do material em larga escala nos países industrializados

A falta de profissionais capacitados em técnicas de construção em terra bruta.

Falta de normatização e padronização.

Falta de conscientização pública e comoção de apoio institucional.

Competitividade de interprofissionais e outros materiais de construção.

\subsection{Métodos construtivos}

Existem várias metodologias construtivas de utilização da terra crua. Geralmente, elas são agrupadas para facilitar a compreensão. Existem os métodos "diretos", onde a terra bruta é transformada e usada in situ; e 
os métodos "indiretos", que consistem em produzir unidades que são secas e associadas a um produto ligante embutido na alvenaria (PISANI, 2004).

Os métodos diretos são divididos em duas classes: modelagem direta, onde o solo é compactado entre as formas, o que chamamos de "pisé"; ou solo empilhado por vários meios (por canteiros de flores, por pátios, por torrões depositados), que é comumente chamado de sabugo (PISANI, 2004).

Nos métodos indiretos, os elementos são modulados manualmente em diferentes formas (deformados, achatados, torrões cilíndricos, volumes hemisféricos, plano-convexos, piriformes, etc.) ou moldados em molduras de madeira e destinados à alvenaria (PISANI, 2004).

E há também um terceiro grupo que usa reforços de madeira como estrutura. Neste caso, a terra não tem uma função estrutural, mas sim um enchimento ou revestimento (PISANI, 2004).

Existem várias técnicas de construção em terra que serão utilizadas em função do contexto geográfico, estilos de vida, costumes locais, clima e materiais disponíveis.

Neste contexto, as 18 principais técnicas de construção em terra estão descritas na Figura 1.

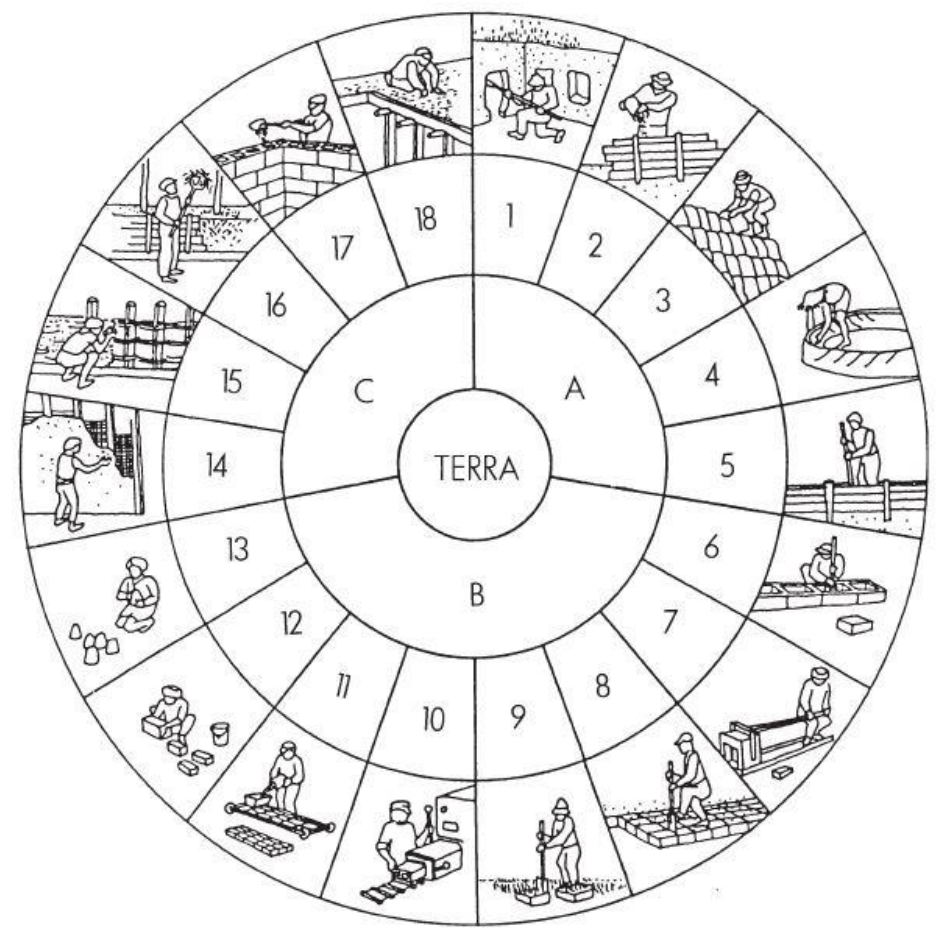

Figura 1 - Técnicas de construção em terra (FERNANDES, 2006).

As técnicas de construção de terra são classificadas de acordo com a forma como a terra é usada no processo de construção (Tabela 1).

\begin{tabular}{|c|c|c|}
\hline $\begin{array}{c}\text { A } \\
\text { Utilização da terra sob a } \\
\text { forma } \\
\text { monolítica e portante }\end{array}$ & $\begin{array}{c}\text { B } \\
\text { Utilização da terra sob a } \\
\text { forma } \\
\text { de alvenaria portante }\end{array}$ & $\begin{array}{c}\text { C } \\
\text { Utilização de terra como } \\
\text { enchimento de uma estrutura } \\
\text { de suporte }\end{array}$ \\
\hline $\begin{array}{l}1 \text { - Terra escavada } \\
2 \text { - Terra plástica } \\
3 \text { - Terra empilhada } \\
4 \text { - Terra modelada } \\
5 \text { - Taipa de pilão }\end{array}$ & $\begin{array}{l}6 \text { - Blocos apiloados } \\
7 \text { - Blocos prensados } \\
8 \text { - Blocos cortados } \\
9 \text { - Torrões de terra } \\
10 \text { - Terra extrudida } \\
11 \text { - Adobe mecânico } \\
12 \text { - Adobe manual } \\
13 \text { - Adobe moldado }\end{array}$ & $\begin{array}{l}14 \text { - Terra de recobrimento } \\
15 \text { - Terra sobre engradado } \\
16 \text { - Terra palha } \\
17 \text { - Terra de enchimento } \\
18 \text { - Terra de cobertura }\end{array}$ \\
\hline
\end{tabular}

Tabela 1 - Técnicas de construção em terra (FERNANDES, 2006). 
A Tabela 2 fornece uma breve descrição das técnicas.

\begin{tabular}{|l|l|}
\hline Técnicas & Descrição \\
\hline Terra escavada & Habitat escavado na profundidade do solo \\
\hline Terra de cobertura & Terra cobrindo uma estrutura construída com outro material \\
\hline Terra de enchimento & Terra que preenche um envelope feito de materiais ocos \\
\hline Terra cortada & Blocos de terra cortados diretamente no solo \\
\hline Terra comprimida & Terra comprimida em moldes ou cofragens \\
\hline Terra modelada & Terra moldada em plástico à mão \\
\hline Terra empilhada & Bolas de terra empilhadas em paredes grossas \\
\hline Terra modelada & Terra moldada em moldes de várias formas \\
\hline Terra extrudida & Terra extrudada usando uma máquina \\
\hline Terra plástica & Terra plástica em uma forma ou molde \\
\hline Terra palha & O material leve consiste em uma pasta de argila ligada às fibras \\
\hline Terra de recobrimento & Terra misturada com fibras que cobre um suporte em camadas finas \\
\hline
\end{tabular}

Tabela 2 - Diferentes técnicas de construção de terra (ITULAMYA, 2019).

Como pode ser observado, há diversos métodos relacionados que utilizam a terra crua como material de base. Qual método utilizar vai depender da composição da terra que se tem disponível, no conhecimento tecnico de quem vai utilizalá-la e do tipo de construção que se pretende fazer.

\section{Considerações finais}

A terra crua é utilizada como material construtivo há mais de 9000 anos por todo o mundo. Entretanto, a partir do século XIX, tornou-se cada vez menos comum em comparação com os mais diversos tipos de materiais, como o concreto e o aço, considerados mais modernos e duráveis.

No entanto, sabendo-se que o setor de construção civil é um dos que mais consomem materiais e causam impactos ambientais, cada vez mais se incentivam estudos de desenvolvimento de materiais e métodos construtivos que sejam menos impactantes.

Nesse contexto, a terra crua começa a voltar a ter destaque por arquitetos e construtores, pois é um material com muitas vantagens econômicas, ambientais e de conforto. Além de existem diversos métodos construtivos que podem ser utilizados de acordo com o tipo de terra e de construção que se deseja fazer.

Desse modo, considerando os pontos abordados nesse trabalho, conclui-se que esse matérial pode ser considerado um bom matérial sustentável, pois dentre tantas vantagens, ele é de baixo impacto ambiental se comparado a outros materiais construtivos. Contudo, ainda tem suas limitações e precisa ser mais difundido entre as construções modernas.

\section{Referências Bibliográficas}

CARVALHO, T. de; LOPES, W. (2012). A arquitetura de terra e o desenvolvimento sustentável na construção civil. In: CONGRESSO NORTE NORDESTE DE PESQUISA E INOVAÇÃO, 7., 2012, Palmas. Anais [...].Palmas: CONEPI, 2012. p. 1 -7.

CORDEIRO, C. et al. (2019). Construções vernáculas em terra: perspectiva histórica, técnica e contemporânea da taipa de mão. PARC Pesquisa em Arquitetura e Construção, Campinas, SP, v. 10, p. e019006, jan. 2019. ISSN 1980-6809. Disponível em: 
<https://periodicos.sbu.unicamp.br/ojs/index.php/parc/article/view/8651212>. Acesso em: 02 jan. 2019. doi:https://doi.org/10.20396/parc.v10i0.8651212.

Fernandes, M. (2006). Técnicas de construção em terra. Terra, forma de construir: Arquitectura, antropologia, arqueologia. Lisboa: Argumentum. Escola Superior Gallaecia. 1 ed. p. 144. http://www.restapia.es/files/14804.

França, S., et al. (2019). Proknow-c: da seleção de um portfólio de artigos à análise sistêmica sobre blocos de terra comprimida. Pensar Acadêmico, Manhuaçu, v. 17, n. 3, p. 291-308. DOI : 10.21576/pa.2019v17i3.838.

Gomes et al. (2019). Construção com base em terra: contributo para a ecoeficiência na construção. [Conferencie]. Sustentabilidade na Gestão Ambiental, Conferência Internacional à Lisboa, Portugal: IST Instituto Superior Técnico, p. 1-9 https://run.unl.pt/handle/10362/83184.

MARCONI, M. A.; LAKATOS, E. M. Técnicas de Pesquisa: planejamento e execução de pesquisas, amostragens e técnicas de pesquisa, elaboração, análise e interpretação de dados. 5. Ed. São Paulo: Atlas, 2003.

Itulamya, L. (2019). Valorisation des gisements argileux pour la fabrication des blocs de terre comprime. [Thèse de Doctorat. Université Liège]. Orbi.uliege.be. https://orbi. uliege.be /bitstream/2268/237179/1/Construct.terre.pdf

Pisani, M. (2004). Taipas: a arquitetura de terra. Sinergia, São Paulo, v. 5, n. 1, p. 09-15. https://www.researchgate.net/profile/Maria_Augusta_Pisani/publication/271829655_T AIPAS_A_ARQUITETURA_DE_TERRA/links/54d̄27cd10cf2b0c61469bf06/TAIPAS-A-ARQUUITETURA-DETERRA.pdf.

Oliva, J-P., Courgey, S., (2010). L'isolation thermique écologique. Terre Vivante, 2010. ISBN 978-2-914717-885. 2010. 